\title{
Incidence and Etiology of Recumbent Cows in Veterinary College Hospital at Namakkal Tamilnadu during the period 2015 to 2019
}

\author{
S. Sivaraman*, G. Vijayakumar, G. A. Balasubramaniam, \\ S. Dharmaseelan and P. Selvaraj
}
Department of Veterinary Clinical Medicine, Veterinary College and Institute, Namakkal, Tamil Nadu Veterinary and Animal Sciences University, Tamil Nadu 637 002, India
*Corresponding author

\section{A B S T R A C T}

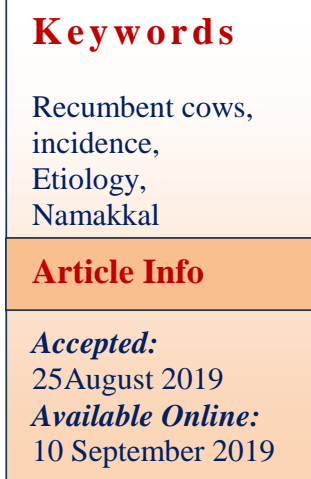

Keywords

Recumbent cows, incidence,

Etiology,

Namakka

Article Info

Accepted:

Available Online:

10 September 2019
Recumbent cow syndrome refers to cows that become recumbent and fail to rise. Five hundred and fifty six cows presented in recumbency to veterinary hospital, Namakkal district of Tamil Nadu during the period June 2015 to May 2019 were analyzed for incidence and aetiologies. Jersey cross bred cattle and cow in the $4-5$ years age group had highest incidence of recumbent cow syndrome. The various etiologies observed included metabolic disorders $(n=186 ; 33.45$ per cent), abdominal dysfunction $(n=$ 132; 23.74 per cent), infectious causes $(n=42 ; 7.55$ per cent), intoxication $(\mathrm{n}=17 ; 3.06$ per cent $)$ and musculoskeletal disorders $(\mathrm{n}=179 ; 32.19$ per cent).

\section{Introduction}

Recumbent cow syndrome refers to cows that become recumbent and fail to rise. Recumbent cattle can present a diagnostic challenge to veterinarians and is a major concern among dairy farmers which leads to economic loss. The syndrome is caused by several etiological factors including hypocalcaemia, mineral deficiencies, septicaemia, muscle damage, infectious disease, intoxication, etc. Accurate data on the incidence of recumbent cow are not available because of variations in the nomenclature used and accuracy of diagnosis. Regardless of the cause, the prolonged recumbency results in varying degrees of ischemic necrosis of major muscles of the hind limbs, particularly the semi tendious muscle and muscles caudal to stifle. Prolonged compression of the muscle leads to tissue anoxia, cell damage and inflammation which cause swelling; the swelling causes a further increase in pressure which limits tissue perfusion and leads to a detrimental cascade of events. Most recently the term downer cow was used to demonstrate non ambulatory cattle 
recumbent for at least $24 \mathrm{hrs}$ without any obvious reasons. Once the animal become recumbent due to any primary etiology later it will go for the secondary recumbency which will complicate the cases and its recovery. The etiologies and the incidence may vary from Institute to the other and from one state to other state. It becomes essential to document these information for knowledge, management of such cases and for future work This study was undertaken to record the incidence and etiology of the recumbent cows presented to Veterinary Hospital, Veterinary College and Research Institute, Namakkal in Tamil Nadu.

\section{Materials and Methods}

Cows that were brought to the Large Animal Medical unit of Veterinary Clinical Complex, Veterinary College and Research Institute, Namakkal in recumbency were utilized for the study. These were subjected to detailed clinical examination, haemato-biochemistry, radiography, ultrasonography and liver biopsy. Clinical examination of the animal was undertaken as per standard methods. Five millilitres of venous blood was collected in vacutainer tubes containing ethylene di amine tetra acetate (EDTA $\mathrm{K}_{3}$ ) as anticoagulant for haematological investigation. The animals which were suspected for skeletal involvement were subjected radiograph using Wipro GE 525 DX X ray unit. All the animals under study were subjected to ultrasonographic examination using Esoate Mylab 40 Vet Ultrasound machine using $2.0-3.5 \mathrm{MHz}$ transducer. The data obtained were analysed using statistical analysis and presented Snedecor, G. W. and W. G. Cochran, (1994).

\section{Results and Discussion}

\section{Incidence}

The incidence of recumbent cow syndrome in the presence study was 7.39 per cent of various disease conditions among the cattle brought to Veterinary Clinical Complex, Veterinary College and Research Institute, Namakkal (Chart 1). Jersey cross bred cattle had highest (58.99 per cent) incidence of recumbent cow syndrome followed by Holstein Friesian cattle (34.84 per cent) (Chart 2). This over representation of female and Jersey cross bred cattle in the present study could be attributed to higher proportion of female and Jersey cross bred among other breeds in the region under study. Highest incidence of recumbent cow syndrome was noticed in $4-5$ years age group (23.92 per cent) followed by 3 - 4 years (18.71 per cent) and 2 -3 years (16.91 per cent) (Chart 3 ). This could be due to higher per cent of animals in this age group maintained by farmers owing to the higher production levels. Sasikala, (2016), Periyasamy, (2017) and Reddy, (2019) reported similar higher incidence of medical disorders in female cattle and Jersey cross bred cows in their study in the same geographical location.

Periparturient animals (59.71 per cent) had highest incidence of recumbent cow syndrome when compared to the pregnant (23.02 per cent) and lactating cows (17.27 per cent) (Chart 4). This could be due to metabolic disturbances and various disease conditions that commonly occur at higher rate when compared to the pregnancy / lactation $\mathrm{s}$ reported by Smith, (2009), Van Metre et al., (2001) reported that downer cows were a common presentation in the periparturient period. The downer cow syndrome episode frequently occurred within 24 hours of calving in dairy cows. Highly productive cows and older cows were at greater risk of downer cow syndrome. Clinical hypocalcemia, stillbirth, and dystocia were all identified as risk factors for downer cow syndrome in dairy cattle in the first 30 days after parturition Constable et al., (2017) reported that the downer cows were high producers (48 per cent) and 
approximately 58 per cent of cases occurred within one day of parturition and 37 per cent occurred during the first 100 days of lactation. Higher incidence of recumbent cows in periparturient period in the present study was supported by the reports and observations of the Van Metre et al., (2001) and Constable et al., (2017).

\section{Etiology}

Five hundred and fifty six recumbent cow were presented during the study period and the various etiologies included were metabolic disorders ( $\mathrm{n}=186 ; 33.45$ per cent), abdominal dysfunction $(\mathrm{n}=132 ; 23.74$ per cent $)$, infectious causes $(n=42 ; 7.55$ per cent), intoxication $\quad(n=17 ; 3.06$ per cent $)$ and musculoskeletal disorders $(n=179 ; 32.19$ per cent) (Chart 5). Caple, (1986) reported that there was no universal cause of the downer cow syndrome, but it was most frequently a sequela to milk fever where complications, such as muscle necrosis and nerve paralysis, could arise because of delayed or insufficient calcium replacement.

Doonan et al., 2003 Cows were at greatest risk of disease and death in the weeks just after calving. Green et al., 2008 opined that the risks included metabolic illnesses such as hypocalcemia and ketosis, infectious diseases such as mastitis and metritis, and other maladies such as dystocia and hoof and leg injuries that caused lameness. Fenwick, 1969 reported that non ambulatory cows were unable or unwilling to stand and remained recumbent for $\geq 12 \mathrm{~h}$. Cox, (1988) reported that regardless of cause, an extended period of recumbency initiated secondary damage to the muscles and nerve tissue, causing a condition described as secondary recumbency, which in turn increased the risk of compartmentalization and crushing syndrome. The various etiologies for the recumbency noticed in the present study were supported by the reports of the above authors.

\section{Recumbent cows due to Metabolic disorders}

The various etiologies among the metabolic disorder (186 cases) in the present study were hypophosphatemia (38.17 per cent), hypophosphatemia with hypocalcemia (34.95 per cent), hypokalemia (17.74 per cent) hypocalcemia (7.53 per cent) and hypomagnesaemia (1.61 per cent) (Chart 6). Gahlawat et al., (2007) reported that hypophosphatemia had been a predisposing factor for typical periparturient diseases of dairy animals such as the post parturient haemoglobinuria and downer cow syndrome. Hypophosphatemia was frequently associated with hypocalcaemia in early lactating cows and withhypokalaemia in cows with pronounced or prolonged feedintake depression. Kojouri, (2003) reported that hypophosphatemia was a major cause of prolonged sternal recumbency and poor response to routine therapy for Milk Fever, and it was thought that this resulted in a cow that fail to rise after routine treatment. Hypophosphatemia, hypocalcemia and hypokalemia contributing for the recumbency in the cows under present study were in concurrence with the reports of the above authors.

\section{Recumbent cows due to abdominal dysfunction}

The various abdominal dysfunctions noticed in recumbent cows in the present study were peritonitis (43.18 per cent), reticular disorder (22.73 per cent), ileus (14.39 per cent), rumen impaction (10.61 per cent) and rumen lactacidosis (9.09 per cent). Hajighahramani and Ghane, 2010 reported that in severe cases of traumatic peritonitis, reticular affections and intestinal involvement, the animal might become recumbent. The recumbency due to abdominal dysfunctions in cows under the present study was in agreement with the reports of the following authors. 
Chart. 1 Incidence of recumbent cows at Veterinary College and Research Institute,

Namakkal during June 2015 to May 2019

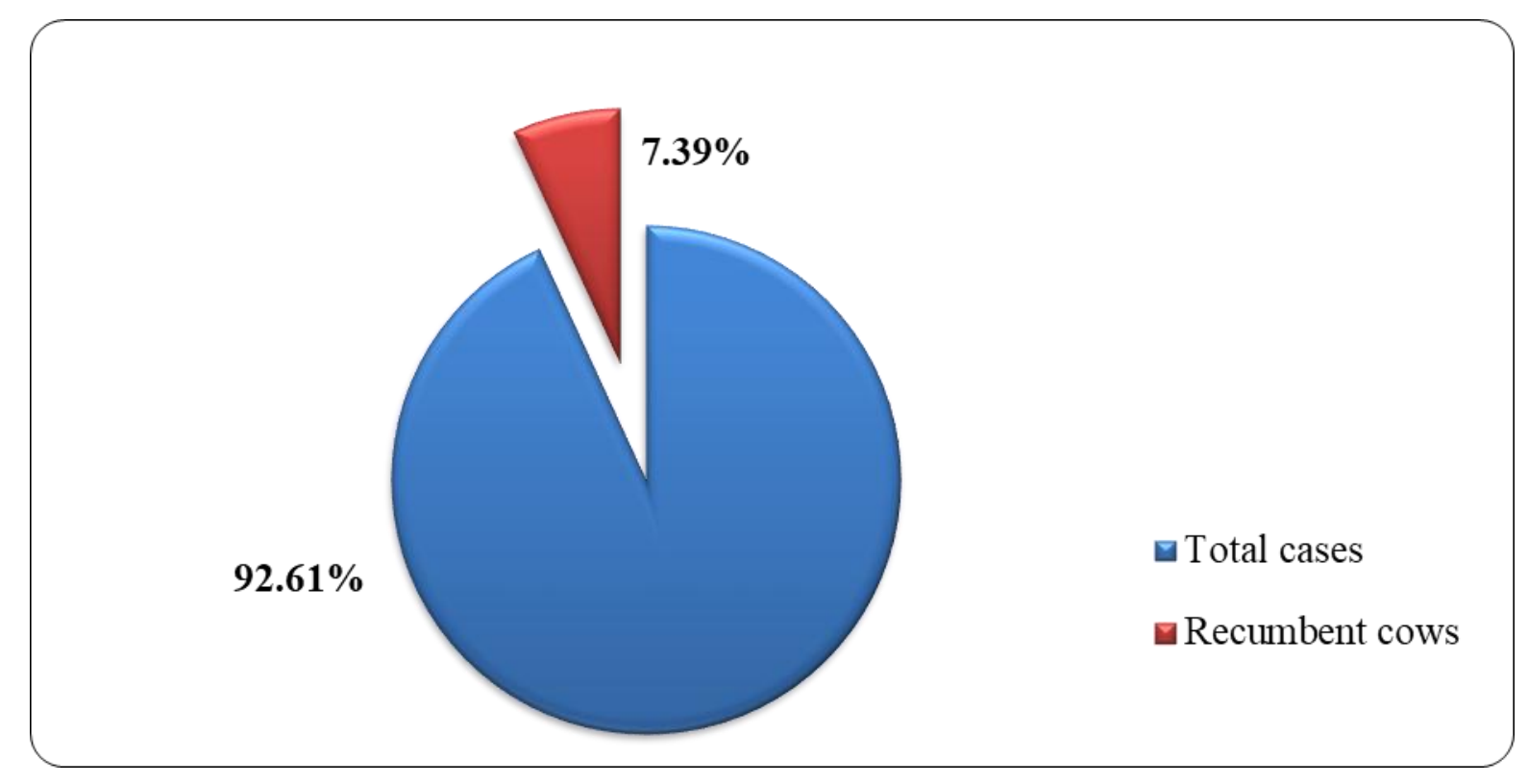

Chart.2 Age wise incidence of recumbent cows at Veterinary College and Research Institute, Namakkal during June 2015 to May 2019

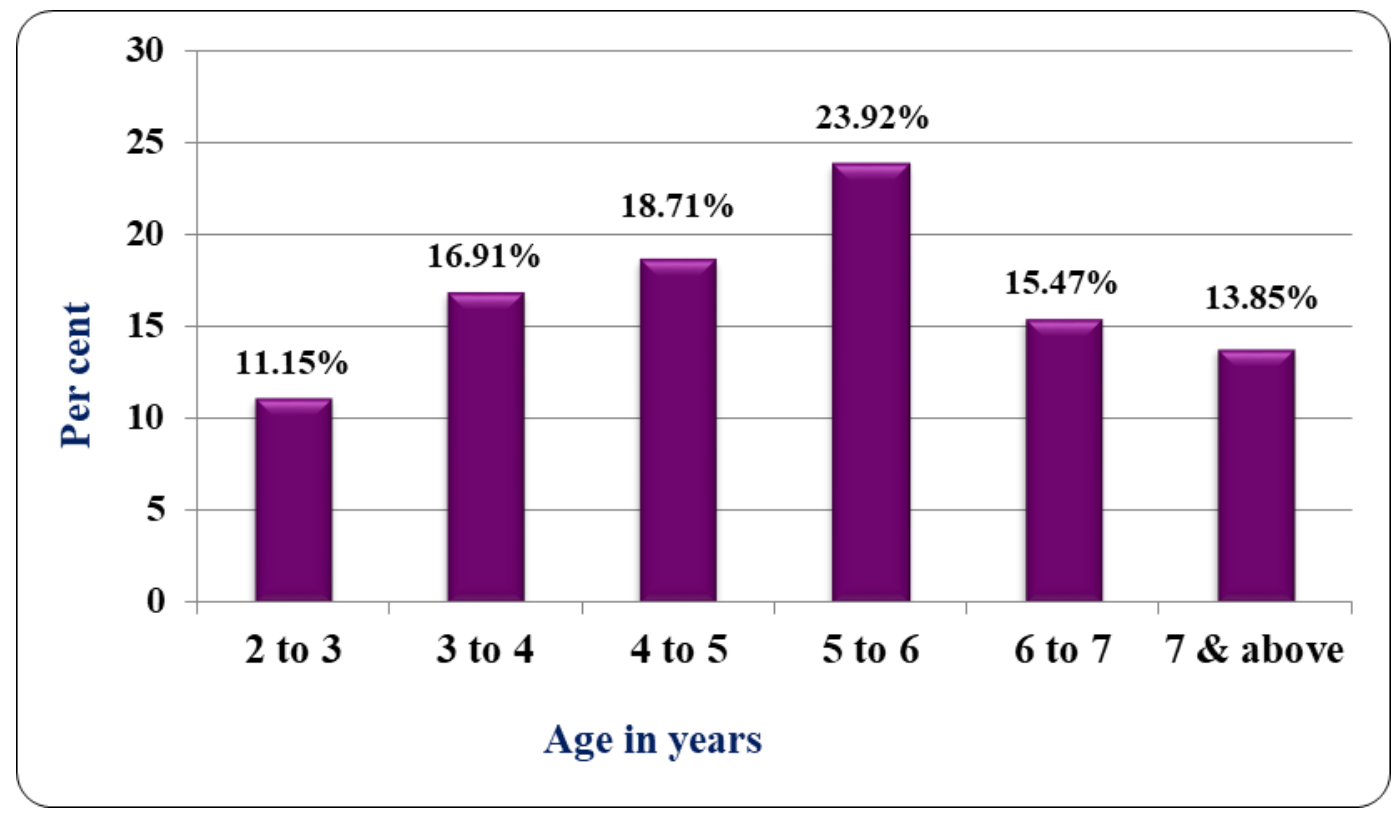


Chart.3 Breed wise incidence of recumbent cows at Veterinary College and Research Institute, Namakkal during June 2015 to May 2019

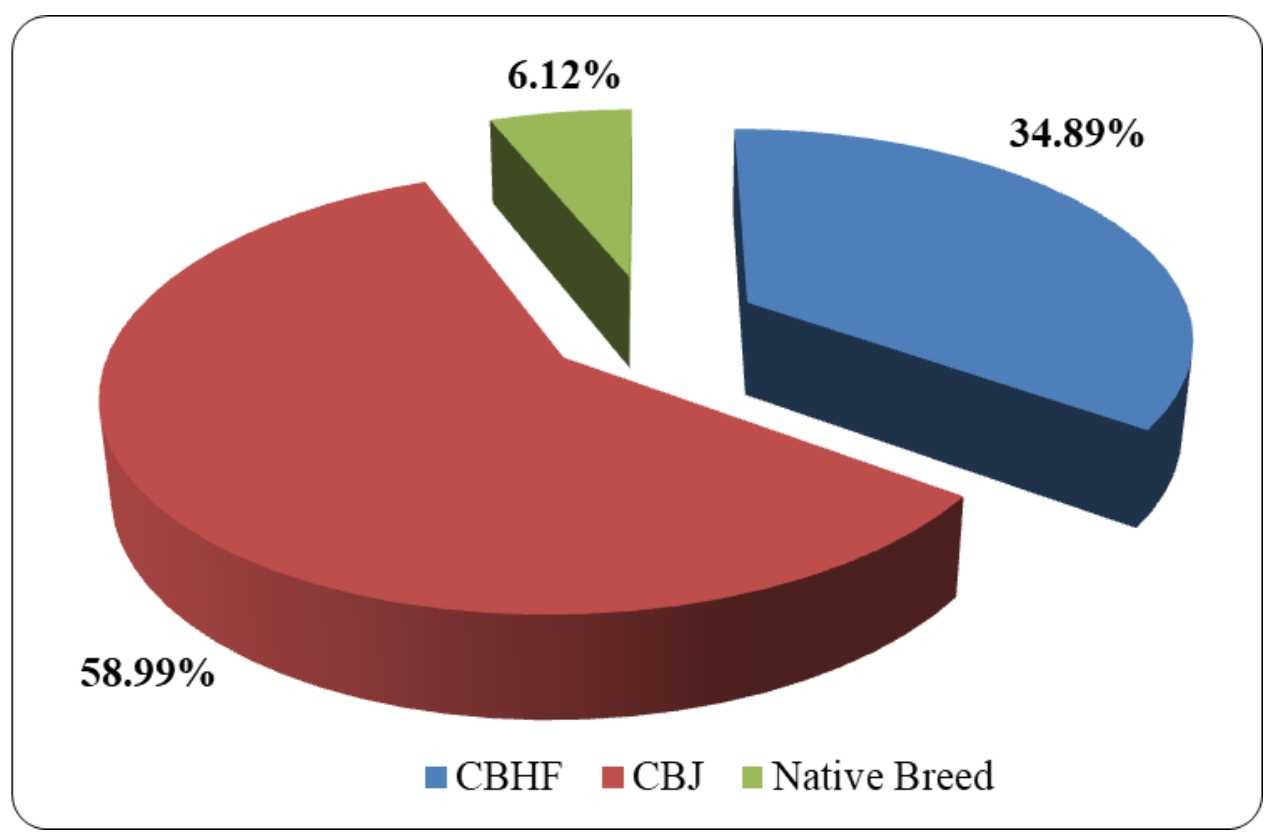

Chart.4 Incidence of recumbent cows at various stages of pregnancy and lactation during June 2015 to May 2019

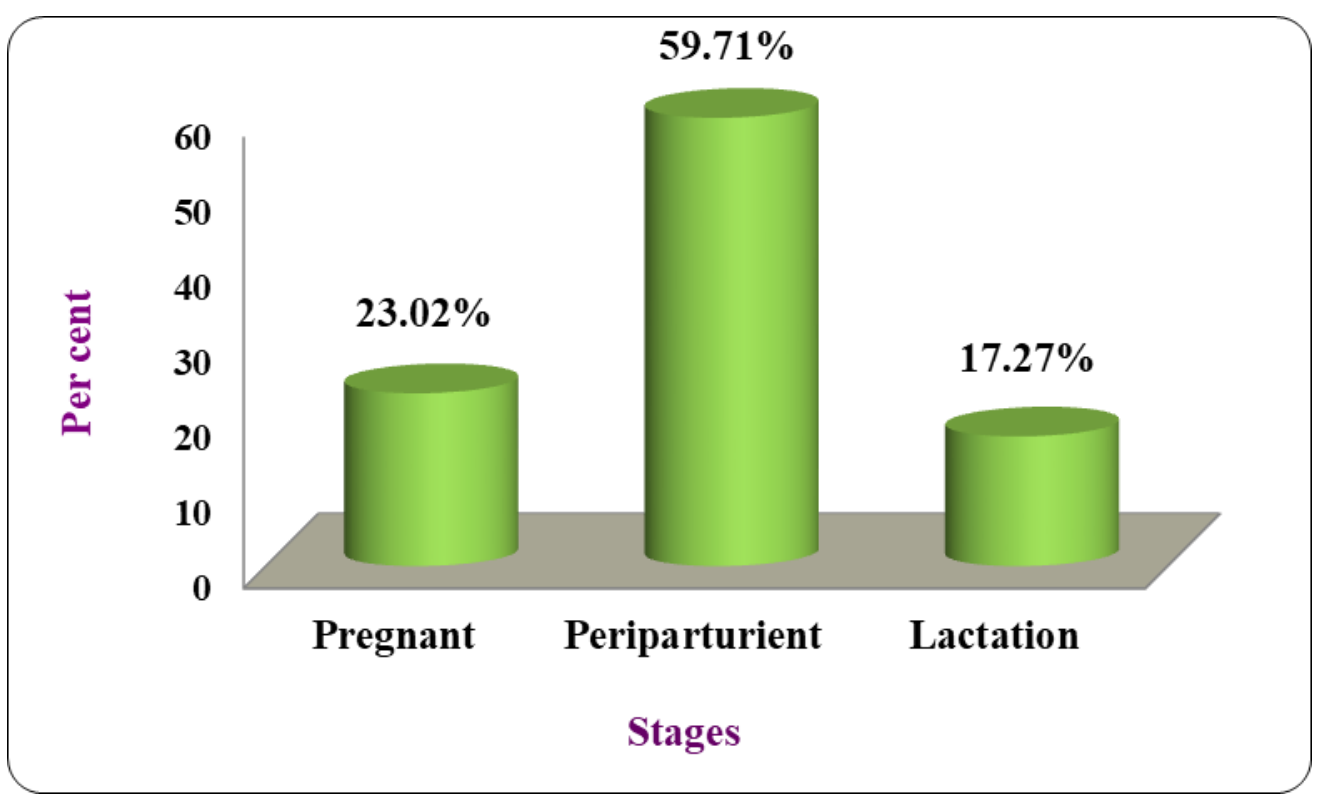


Chart.5 Various etiologies of recumbent cows presented to Veterinary College and Research Institute, Namakkal during June 2015 to May 2019

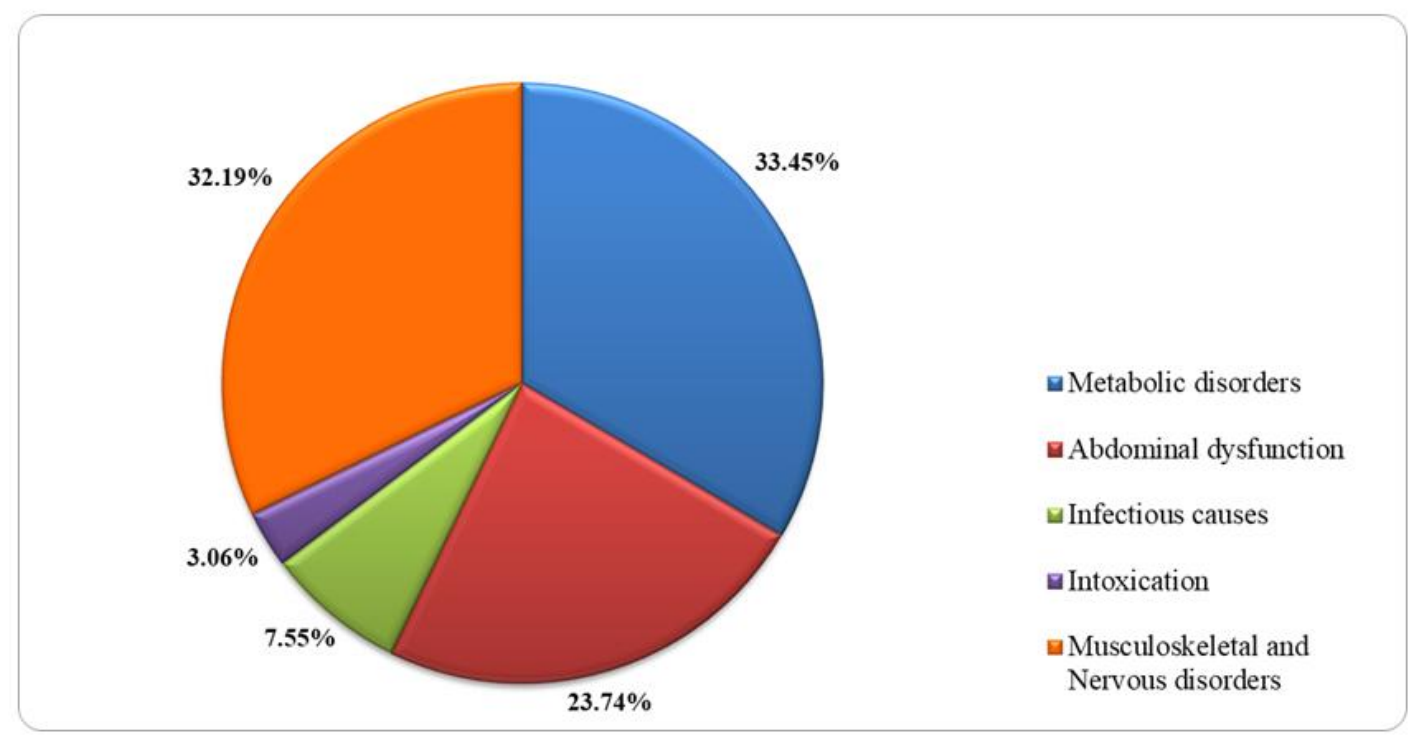

\section{Recumbent cows due to infectious causes}

Septicemia (61.90 per cent), mastitis (14.29 per cent) and blood protozoan disease $(23.81$ per cent) were observed during the present study in recumbent cows due to infectious causes. Constable et al., (2017) had reported that septicemia due to various causes, anaemia, electrolyte disturbances and fluid loss could cause recumbency in cows.

\section{Recumbent cows due to intoxication}

Botulism (82.35 per cent) and organophosphorus intoxication (17.64 per cent) comprised causes of recumbency due to intoxication in the present study. Haagsma and TerLaak, 1978 Bruckstein and Tromp, (2001) and Yeruham et al., (2003) opined that chronic botulism could be the cause of downer cow syndrome and needed detailed analysis of rumen fluid, feces and toxin analysis.

\section{Recumbent cows due to musculoskeletal and nervous disorders}

The various musculoskeletal and nervous disorders contributing for recumbent cow in the presence study included peroneal nerve paralysis (28.49 per cent),radial nerve paralysis (13.41 per cent), stifle joint injury (21.79 per cent), tibial nerve paralysis (14.53 per cent), sciatic nerve paresis(7.82 per cent), hip dislocation (6.70 per cent), gastrocnemius muscle rupture (3.35 per cent) and others including obturator nerve paresis, hip fracture, femur fracture and peroneustersius muscle rupture(7 per cent). Huxley, (2006) reported that fractures (femur, pelvis), dislocations (hip, sacro iliac) and muscular (rupture of the hind limb adductors or gastrocnemius or severe bruising due to heavy falls onto concrete could cause be considered as primary causes of recumbency in cattle.

\section{Acknowledgement}

The authors are thankful to the Director of Clinics Tamil Nadu Veterinary and Animal Sciences University, Chennai 600007 and the Dean, Veterinary College and Research Institute, Namakkal 637002 for the facilities provided during the study. 


\section{References}

Bruckstein, S., and A.M. Tromp, 2001. Food poisoning in three family dairy herds associated with Clostridium botulinum type B. Israel J. Vet. Med., 56 :95-98.

Caple, I, W. 1986., Downer cow syndrome. In: Howard JL, ed. Current Veterinary Therapy: Food Animal Practice WB Saunders, pp327-328.

Constable, P. D., K. W. Hinchcliff, S. H. Done and W. Grunberg, 2017. Veterinary Medicine - A Textbook of the Diseases of Cattle, Horses, Sheep, Pigs and Goats, $11^{\text {th }}$ edition, Saunders, USA, pp. 436-621.

Cox, V. S., 1988. Nonsystemic causes of the downer cow syndrome. Vet. Clin. North Am. Food Anim. Pract., 4:413-433.

Doonan, G., M. Appelt, and A. Corbin, 2003. Nonambulatory livestock transport: The need of consensus. Can. Vet. J., 44:667-672.

Fenwick, D. C., 1969. The downer cow syndrome. Aust. Vet. J., 45:184-188.

Gahlawat, I., Singh, K., and Kumar, R, 2007. Investigations on oxidative stress in postparturient haemoglobinuria in buffaloes receiving sodium acid phosphate therapy. Italian Journal of Animal Science, 6: 974-977.

Green, A. L., J. E. Lombard, L. P. Garber, B. A. Wagner, and G. W. Hill, 2008. Factors associated with occurrence and recovery of nonambulatory dairy cows in the United States. J. Dairy Sci., 91:2275-2283.

Haagsma J., and E. A. Ter Laak, 1978. A typical cases of type B botulism in cattle caused by supplementary feeding of brewer's grains. Tijdschrift voor Diergeneeskunder 103, 312325.

Hajighahramani, S. and M. Ghane, 2010.
Traumatic reticulperitonitis in cattle of Khorramabad (Center of Lorestan Provenience, West of Iran). Global Vet., 5: 135-139.

Huxley J., 2006. Assessment and management of the recumbent cow. In Pract., 28:176-184.

Kojouri, G. A., 2003. Parturient paresis and its relationship with hypophosphatemia. Acta Veterinaria Scandinavica, 44: P126.

Periyasamy, V., 2017. Clinico pathological evaluation of foreign body syndrome in cattle. M.V.Sc Thesis submitted to Tamil Nadu Veterinary and Animal Sciences University, Chennai, Tamil Nadu.

Reddy, B. S., 2019. Evaluation of gastro intestinal motility disorders in cattle. Ph.D. Thesis submitted to Tamil Nadu Veterinary and Animal Sciences University, Chennai, Tamil Nadu.

Sasikala, K., 2016. Endoscopic evaluation of therapeutic management of diseases of reticulum in cattle. M.V.Sc Thesis submitted to Tamil Nadu Veterinary and Animal Sciences University, Chennai, Tamil Nadu.

Smith, B.P., 2009. Large animal internal medicine. $4^{\text {th }}$ edn., Mosby-Elsevier, St. Louis, Philadelphia, USA pp. 474-478.

Snedecor, G. W. and W. G. Cochran, 1994. Statistical methods (eighth edition). Calcutta, India: Oxford and IBH Publishing Co. pp. 304-307.

Van Metre, D. C., Callan, R. J., and Garry, F. B, 2001.Examination of the musculoskeletal system in recumbent cattle. Compendium, 23: 5-24.

Yeruham, I., D.Elad,, Y. Avidar,, K. Grinberg, D. Tiomkin and A. Monbaz, 2003. Outbreak of botulism type $\mathrm{B}$ in a dairy cattle herd: clinical and epidemiological aspects. Vet. Rec., 153: 270-272.

\section{How to cite this article:}

Sivaraman, S., G. Vijayakumar, G. A. Balasubramaniam, S. Dharmaseelan and Selvaraj, P. 2019. Incidence and Etiology of Recumbent Cows in Veterinary College Hospital at Namakkal Tamilnadu during the period 2015 to 2019. Int.J.Curr.Microbiol.App.Sci. 8(09): 2936- 2942. doi: https://doi.org/10.20546/ijcmas.2019.809.337 